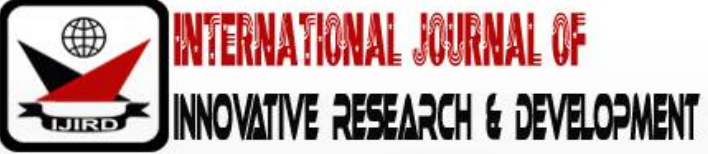

ISSN 2278-0211 (Online)

\section{On Distinctive Features and Categorization of Tewbabi Folk-Game Songs}

\author{
Isaac Asare-Aboagye \\ Tutor, Department of Music and Dance, Berekum College of Education, Ghana \\ Emmanuel Obed Acquah \\ Associate Professor, Department of Music Education, \\ University of Education, Winneba, Ghana
}

\begin{abstract}
:
Folk-game songs of the Tewbabi people of Ghana have distinctive features that have great implications in the music curriculum in Ghana. Unfortunately, the significance of many of these folk-game songs in Ghanaian context has not been given much attention to propel its use in the music curriculum in Ghana. The study therefore sought to collect, categorize the folk-game songs among the Tewbabi people of Ghana. It also highlights some educational significance of these folksongs to add to the paucity of literature on Ghanaian folk-games. The study was rooted in the qualitative research paradigm and using ethnographic research design, eight existing folk-game songs were identified and categorized into themes for educational use. The population included two cultural troupes who were purposively sampled to obtain the necessary information for the study. The instruments used for the data were interview, participant observation and personal conversation. It was found out that both transitional folk-game and actualization folk-game songs exist in the Tewbabi community. These folk-game songs have unique characters that have greater impact on the teaching and learning of music in Ghanaian basic schools. It is therefore significant that teachers make use of Tewbabi folk game songs to address conceptual problems in music teaching and learning.
\end{abstract}

Keywords: Folk-game songs, categorization, transitional, and actualization

\section{Introduction}

Folk songs grow out of the folk culture of ethnic groups, regions and nations. Folk-songs are therefore found all over the world including Africa. In Ghanaian society for instance, folk-songs are found in the daily activities and social events of the people. Some of these activities are found in festivals, naming ceremonies, worships, communal labour, installation of chiefs and others. The folk-songs are found in lullabies or cradles, children songs, folk games, dirges and in recreational musical performances. A lot of scholars have been associated with traditional music and folk-songs either in compilations or discourse in Ghana and Africa. However, the peculiarity of folk-game songs in Tewbabi Traditional area in the Berekum West District in the Bono Region of Ghana has not been given the needed attention. The people of Tewbabi traditional area share certain cultural fundamental similarities with other Akan people as described by Rosman and Rubel (1998) cited in Meriwa (2017) as cultural universals. The Tewbabi people observe a lot of traditional musical activities in their oramedia performances such as in folktales and folklores. This aligns with what Nketia (2004) describes as an index of a living community. Tewbabi as a living community attaches importance to the indigenous music and traditional games within the community. It is worthy of note that the new Ghanaian School curriculum has addressed the need to use musical games in teaching and learning in Ghanaian schools. The Creative Arts curriculum which prepares the learner in creative minded activities spells out the importance of folk-games in creative thinking. This has called for teachers handling the subject to be more proactive in using folk-game songs in their teaching-learning process. Acquah et al. (2015) were of the view that musical games in the child's life coupled with other related subject activities are important to develop inherent forms of intelligence such as emotional, musical, bodily motor and spatial intelligence which contribute to the total well being of the child. This affirms Loy-Ee (2015) cited in Acquah et al (2015), that children's familiarity with the sounds of words and letters (musical games) can serve as the bedrock for learning the corresponding graphical representations in print. However, the researchers have observed that the folk-game songs are not readily available in Ghanaian schools, which facilitators can fall on to teach.

Furthermore, preliminary studies revealed that teachers choose any available folk-game song without properly aligning it to the concept being taught. They had little or no knowledge about the kind of themes embedded in the chosen folk-game songs to enable them select which one to choose, for what and in which context. These negative observations made during the preliminary studies have serious impact on the teaching and learning of music in the area. It is against 
this background that this study became very significant to collect some existing folk-game songs among the people of Tewbabi in the Bono Region of Ghana and categorize them for educational purposes.

\section{Theoretical Framework}

The study was guided by the Behaviourists theory propounded by Skinner (1965) as used in the work of Gray and MacBlain (2015) postulating that the theory regards all behaviour as a response to a stimulus. They assume that everything we do is determined by the environment we are in, which provides stimuli to which we respond, and the environments we have been in the past, which caused us to learn to respond to stimuli in particular ways. This theory provides the learning experiences that enable African children to acquire knowledge and understanding of the traditional music and dance of their environment and those of their neighbours. In the same thought, Acquah and Boahen (2015) explained how Africans heavily rely on Western musical traditions with less attention on the African folk tradition. The theory therefore links to the participatory behaviour of performing folk songs, folklore, folk-game and traditional music in the cultural community as it may transcend to formal educational instruction. Children learn from their parent cultures through playing and interacting with their indigenous materials.

\section{Related Literature}

\subsection{Folk-game Songs}

Generally, Games are those forms of individual or team competition played to a decision according to agreed rules. Games during this respect are understood as systems delineated by rules which create a separate sphere of complex meanings. Thus, the term today is widely used to mark the 'special place in time and space created by a game' (Salen \& Zimmerman, 2004 as cited in Brewu, 2009). They are voluntary and non-productive and are played outside everyday reality, in their territories by their characters. Games help small minds and imaginations to mature, provide children with an opportunity to act out roles, make choices, and knowledge for the joy of winning and therefore the disappointment of losing. The folk-game song is an organised game that has unique features in performance. It is structured with rules and regulations governing and needs no special equipment and instruments in playing. The mode of learning or playing is taught by observing and practice. It passes from generation to generation as the tradition stands the test of time. In support, Quay \& Damico (1993) explain folk-game as 'a form of structured play, it has an objective, rules, variability and generally needs no special equipment or specific playing area' (p.1). This suggests that folk-game songs are structured games that are played under specified rules that need no specialised person and passes on from generation to generation.

Furthermore, Folk-game songs are usually played in open or closed places depending on the form or type of the game. There are no restrictions but strict rules which are officiated by the leader of the group (Akuoko, 2010). Folk games involve movements as squating and singing amidst clapping and running depending on the game type. The rules and equipment in the folk-game song may vary. If a shorter game becomes necessary, the players can simply change the rules to achieve the goal (Akuoko, 2010). It is well noted that folk-game songs are well structured and always aimed at a specified objective. It appears folk-games are synonymous with traditional games passed along informally from one group to another. Folk-games, like the games of today, had the same functions that games have had from the beginning of the human race: they amused, instructed, and inspired. They reflected the values and beliefs of their parent cultures (Nketia, 1966).

In an article, Akuoko (2010) categorised the folk-games of the Akan people of Ghana into three: Games solely for boys, girls only and then games for boys and girls. He gave examples of each of the games as follows:

- Games solely for boys e.g. 'Antoakyire' (Don't look back), Playing marbles, shooting of birds, 'Sansankroma' (the hawk), 'oware' (Wari) among others.

- Girls only: 'Aso', 'Ampe' among others.

- Boys and girls: 'Siisiisii', 'Finding your lover', 'Ahyehyzaba', 'Hide and seek', 'Ahuntahunta', etc. (Akuoko, 2010)

Just as traditional music is often put into three categories, namely, occasional, incidental and recreational, according to the purpose and event for which it is being performed (Amuah et al., 2017). It is in the same way that Tewbabi folk-game songs could also be categorised for educational purposes. On types of folk-games associated with children around the world, Akuoko (2010) suggested three types, namely; Boy's only, Girl's only, and Both Sexes children's folk-games. Although Acquah et al (2015) did not categorise traditional games, they noted that most Ghanaian traditional games can be played by both sexes group.

Again, Schnell (2013) classified folk songs under three broad headings, namely; ballad, lyrics and dialogue songs. She further argued that folk songs are not ballad but ballads are folk songs, since a ballad is a narrative form of storytelling which depends mostly on love, religion, recreation or any type of topics. She linked the lyrics to emotions rather than actions and the dialogue to the dramatic events which is usually between two people's views. All these categorizations were based on the text content of the songs without taking into consideration its educational factor. The categorization in this study takes into consideration the implications for educational use.

\subsection{Role of Song Text in Folk-games}

Folk-games are associated with songs that set the rules and the style of the performance of the game. Song texts and its rhymes or cadences in folk-games play a vital role in the game and in human behaviour; hence the text of the songs cannot be left untreated. Merriam (1964) suggests that one of the most obvious sources for the understanding of human behaviour in connection with music is song text. He is of the view that texts, of course, are language behaviour rather than 
music sound but they are an integral part of the music and there is clear cut evidence that the language used in connection with music differs from that of ordinary discourse. In support of Merriam's assertion, Nketia (1974) had a similar view:

The treatment of the songs as a form of speech utterances arises not only from stylistic considerate or from consciousness of the features of the analogue of speech and music: it is also inspired by the importance of the song of verbal communication, a medium for creative verbal expression which can reflect both personal and social experiences (p.189)

Music and language are interrelated, and music is affected by language, speech melody which sets up certain patterns of sound in rhythm and harmonies that must be followed at least to some extent in music, if the music text is to be understood by the listener. A striking feature of song texts in Africa is that, in songs, the individual or the group could express deep-seated feelings not permissibly verbalised in other contexts. Again, the text in a song should be heard and understood, also, the melodic line should reflect and underscore the meaning and emotion of the text as stated in Morford and Lenardon (1999). It is possible that one can say publicly in songs what you cannot say in the presence of someone, thus, Tracey (1954) cited in Warren (1973) emphasises the speaking of the African, that one can say publicly in songs what cannot be said to a man's face and this is one of the ways African society takes to take care of a spiritually healthy community.

The song text in folk-games is believed to reflect strong feelings and spiritual connotations that make the game unique in nature. Some of the song texts inspire, insult, educate and entertain in such a way that one would learn and transform for the betterment of his lifestyle. Using it in the classroom therefore has a very significant impact to develop the morals of pupils and enhance learning. As Warren (1973) documented, during Apos festival celebrated yearly by the Bono of Techiman, songs are used to express communal sentiments about certain aspects of character such as selling of stool-lands and unfair judgment on the part of the chiefs and the elders of the people. In support, Nketia (1974) asserts that songs may be intended to entertain, inform, praise, insult, exhort, warn or inspire their audiences or perform similar functions. The reflective songs are used to recount the good deeds or bad deeds of individuals in the communities such as kings, dead or alive, commoners and supernatural beings, they may relate to the past or present. On the other hand, some folk-game song texts have a true reflection of what both Warren (1973) and Nketia (1974) wrote, and on the game, it outlines the genesis of the game. Such songs make the playing of the game simple and lively. Song texts may have names of celebrants. This suggests that the song texts in a folk-game deal with the true reflection of our daily activities in life which must be critically observed.

In another development, Brewu (2009) postulated that some of the folk-games involve historical songs. According to him, these historical songs tell the histories and philosophies of the people and the values of the society. This requires some knowledge of oral tradition before one can understand them. With few exceptions, what historical songs provide is not a detailed narration of events, but brief allusions to significant incidents and genealogies. The song text informs the past, present or contemporary issues in a particular society to the consumers. This category of the song is used as a teaching device. Generally, songs talk about the socio-cultural aspects of man's life, which both Nketia (1974) and Brewu agree on.

\section{Methodology}

The study used the qualitative research paradigm and employed ethnographic design (Creswell \& Creswell, 2019). The description of activities of folk-game songs in relation to the Tewbabi cultural context from the point of view of the indigenes made the researchers make explicit and meaningful interpretation of the data collected. As Creswell and Creswell (2019) postulated, the index of ethnographic research design is for the researchers to be with the people for a longer period of time to understand the cultural behaviours of the people and interpret their practices accordingly. We purposively chose two cultural troupes in Tewbabi community. These two cultural troupes; Biakoye and Efiritete have rich folk-game songs which they perform competitively during the festival of the community. We learnt and performed with the two troupes for two years and attended their rehearsals. These troupes have lots of indigenous repertoire but our main focus was on the folk game songs. We observed their activities and performances and collected many of their song repertoire. We also had personal conversation with them to discuss their folk songs which are linked to games. We interviewed them on the background stories of some of the songs and solicited for the meaning of the texts contained in the songs. We asked of their opinion to assist us group the songs collected so that teachers could use them to teach. We used tape recorders and mobile phones to capture the musical sound and videos of some of the live performances of folkgames among the people. Folk-games collected were transcribed, categorized and interpreted for educational use.

\section{Discussion of Findings}

\subsection{Tewbabi Folk-game Songs}

The study identified eight folk-game songs which were commonly played both in the streets and school sessions in the Tewbabi community. The researchers observed how each folk-game song is played and conducted interview as well as personal conversation with the participants. The table below shows the eight-common folk-game songs played in Tewbabi community. 


\begin{tabular}{|c|c|c|}
\hline S/N & Name of Game & English Translation \\
\hline 1. & Tuutuu boj me & Tuutuu, beat me \\
\hline 2. & Teele & Throw and catch \\
\hline 3. & Made & My own \\
\hline 4. & Mpeewa & Slap palm and clap \\
\hline 5. & Bankye ma Akrakuro & Cassava produces dough-nut \\
\hline 6. & Ampe & Ampe \\
\hline 7. & Karikokoo & Carry Cocoa beans \\
8. & Me mmaee! Me mmaee! & My Children! My Children! \\
\hline
\end{tabular}

Table 1: Tewbabi folk-game Songs

\subsection{Thematic Categorisation of Tewbabi Folk-Game Songs}

The study revealed the themes embedded in Tewbabi folk-game songs. The themes were scrutinized and categorized into two. These are Transitional folk-game songs and Actualization folk-game songs.

Transition could be explained as movement, passage or change from one state, stage, subject, and concept to another (Schnell, 2013). In other words, transition is to change or to make something change from one state or condition to another. 'Transitions are changes in the situation for children and those associated with them and can include the transition between home and a play group or pre-school, or care outside the home particularly in early years' (Briggs, 2011, p. 82). Transitions could be explained as a passage of music composed to link one section of music to another (Collins, 2007). Often in music, the transition is the middle section or formal function, while the main theme is the beginning, and the subordinate theme is the ending. Musical transition is an event used to segue between two different sections of a track. Sometimes, two song sections will go together in a very natural way, but other times, you may find the transition unexciting or perhaps a bit shuddering (Mayona, 2016; Kayode, 2013). This implies that transitional folk-game song serves the purpose of changing from one event to the other.

The reason for which something is done or created or for which something exists is what Kayode (2013) identifies as game's purpose. Purposeful is having a purpose or specific aim: to meet the need of the individual and how they learn. Schnell (2013) also described purposeful as person's sense of resolve or determination, have as one's intention or objective. Kayode (2013) further argued that the purpose of composing a musical piece is for it to be performed and materialised. As Connellan (2019) explained, actualisation is to realise in action or make real. Dreams are actualised by means of portraying realistically. Creating and realizing your dream in reality is the act of actualisation (Kapusta, 2018). Music is composed for a purpose and the composer's intention is revealed in the music performance. The table 4 below shows the themes and Tewbabi folk-games' categorisation drawn from the data collected through interviews, observations and personal conversation conducted in the study.

\begin{tabular}{|c|c|c|c|}
\hline S/N & Transitional Folk-Game Songs & \multicolumn{2}{|c|}{ Actualization Folk-Game Songs } \\
\hline 1. & Made & 1. & Mpeewa \\
\hline 2. & Teele & 2. & Tuutuu boj me \\
\hline 3. & Ampe & 3. & Bankye ma Akrakuro \\
\hline 4. & Me mmaee! Me mmaee! & 4. & Karikokoo \\
\hline
\end{tabular}

Table 2: Tewbabi Folk-Game Songs Categorization

\subsubsection{Transitional Folk-game songs}

The study noted that Pempenaa, Teele, and Ampe are folk-game songs grouped under transitional category. The participants revealed that transitional folk-game songs are meant for relaxation and recreational purposes as well as to bridge the ice of people in the learning environment. To them, this category of folk-game songs is usually not based on any specific theme in terms of performance. The participants further explained that the lyrics are mostly not having direct meaning but the melodies are clear and interesting. Mupetami (2014) describes some lyrics of folk-game songs as meaningless and children sing it for fun and entertaining. Briggs (2011) also suggests that transitions occur at various stages in education. She continues to argue that transitions occur between home and school, within school between key stages which may be different buildings, within class with transitions between tasks and groups and between schools. This was also identified in Tewbabi folk-game songs where participants suggested that transitional folk-game songs can serve two main purposes; transition and recreation.

The transition folk-game songs are used to change the environment of the child's progression. Briggs (2011) states that the first major transition stage that children experienced is between home and educational setting. The study confirmed that children bridge the ice from home to school through folk-game songs. The teachers attested that when lessons are introduced with musical games, lessons become interesting and lively. During lesson delivery, folk-game songs/musical games are played to change from a period to another period (Adjepong \&Obeng, 2018; Mayona, 2016). Folk games such as Teele and Madec, among others, could be used to bridge the ice from home to school the environment.

The study revealed that smooth transitions are established when children are engaged in folk-game songs. 'Smooth transitions are essential for children to experience continuity and minimal disruption to their learning security' by Briggs, (2011, p. 89). We observed that children feel refreshed and sound when folk-game songs were used intermittently in lesson delivery. The study again proved that teachers who used folk-game songs in lesson presentations 
established good relationship with children and their families. Teachers working at the pre-school or early grades establish relationship with children and their parents through musical games. The transition folk-game songs are observed to facilitate smooth transition from home to educational setting and between lesson delivery processes.

The recreational songs are meant for entertainment and relaxation (Owusu-Agyemang, 2019; Amuah et al. 2017). Musical games for children are played for fun and entertainment in schools (Mayona, 2016; Mereku, 2013). The participants revealed that children play folk-game songs during break time to entertain themselves. For example, Mpeewa songs like 'Robert' and 'I like', Ampe songs like 'Twi me' and 'Gariwura' among others are used to invigorate the tired minds of pupils and at the eve of the break period.

The study proved that children's recreational activities ensure progression in learning. Children who play musical games during break time feel more refreshed and ready for the following activity in the classroom. Briggs (2011, pp. 9495) states that 'to ensure continuity and progression in children's learning between school and prior learning across curriculum, in and outside school needs recreational activities such as musical or performing talents. The study confirmed that children are refreshed and active in class after break periods in school when they perform folk-game songs or musical games.

The relaxation folk-game songs are played after hard day's work and people engage themselves either as participant or audience. For example: Pempenaa and MemmaeeMemmaee. Children play traditional/musical games (Meriwah, 2017; Mayona, 2016) in the evening to refresh themselves. The study proved that folk-game songs were played in the evenings and moonlight setting in the community. Nowadays, these games are played in schools, picnics and other social gatherings purposely for relaxation. Traditional music and games were meant for relaxation and prepare one for the next action to be taken.

\subsubsection{Actualisation Folk-game Songs}

The study proved that actualisation folk-game songs are realistic in action which brings a particular task in existence. Participants suggested that such Tewbabi folk-game songs are played for a purpose; that is for learning concept, history and fiction, and such folk-game songs could be categorised as Actualisation folk-game songs. This implies that playing Tewbabi folk-game songs manifests in the life of the people's activities and career. Folk-game songs are played for a purpose. Children acquire skills and promote the cultural heritage of their locality through playing and participating in traditional music. This suggests that actualisation folk-game songs have common purpose, realistic in action and results oriented.

Tewbabi folk-game songs could be used to acquire concept in music and other disciplines in education. Children can acquire basic skills, rhythmic concept and melody through traditional music as well as musical games (Mayona, 2016; Acquah et al., 2015; Kayode, 2013). Bankye ma Akrakuro, Anhwswoakyire, and Mpeewa game songs' rhythms control the game practice which forms basis of rhythmic concept. We observed how children played and sang in folk-games; the rhythm was developed intuitively, and this can serve as a good resource material in teaching and learning of music, since the teaching of rhythmic concept becomes difficult when teaching in abstract. Mayona (2016) cited Kodaly's affirmation of using children's folk songs to teach music for developing rhythmic skills of the child. The Bankye ma Akrakuro as used in stone passing game, for instance, has a rhythmic effect on the child, in that; the stone is passed from a performer to performer on the beat and the rhythm-controlled performers. To Mereku (2013), the sound created 'pass-grab' in the stone passing game regulates the game's song which is the beat. When one is off from the rhythm, his chance of landing or passing on the stone to co-performer on time (metre) is uncertain and this results to being eliminated from the game.

Other related topic which the researchers observed was the concentration of the melodic contour of the song. The participating teacher sang the song without involving stone-passing severally which the children grasp and repeated. Like Mayona (2016) stated, 'Children grasp song related to games easier than ordinary song which the melody of such songs is identified (p.74). The children sang it nicely without any accompaniment as used in the game. The concept of melody in music was achieved through the single line expressed by the individual learners.

In other related disciplines such as Mathematics, the Mpeewa can be used to teach the concept of multiples of numbers. The findings revealed that play the Mpeewa game song as they learn the concept of 'Multiples of Two' which made them become comfortable to call out the numbers without difficulty. As noted in the works of Mayona (2016) as well as Adjepong and Obeng (2018), classroom observational children develop their intellectual skills through musical games. This suggests that folk-game songs, which are used to teach and develop concepts, have the purpose of being actualized in music teaching and learning.

\subsection{Musical Scores and Functionality of Tewbabi Folk-game Songs}

Four of the folk-game songs were randomly selected and scored to enable teachers to learn them and assist their pupils to play with them. 


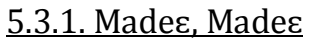

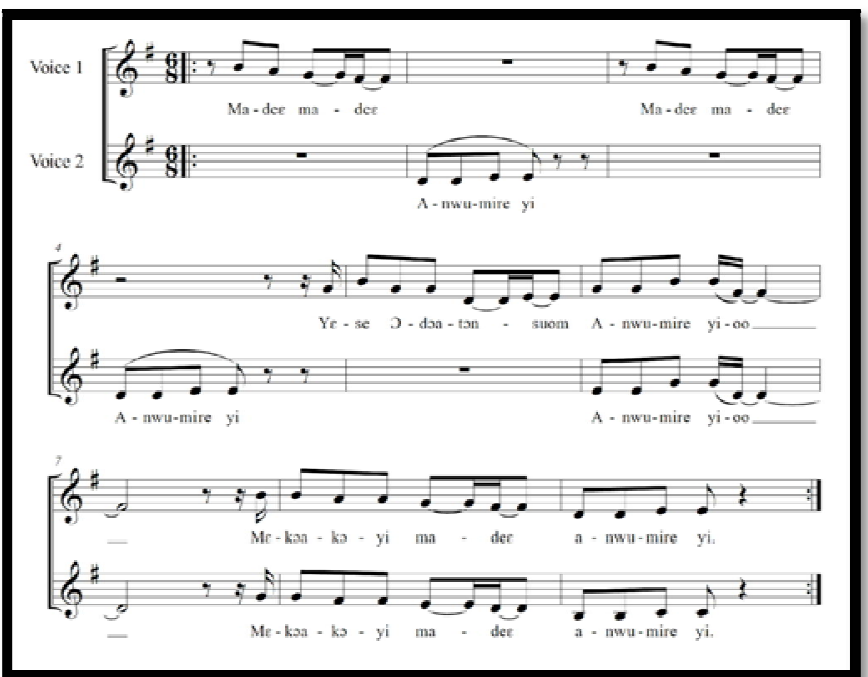

Figure 1: Madec, Madec

5.3.2. Tuutuu Boว Me

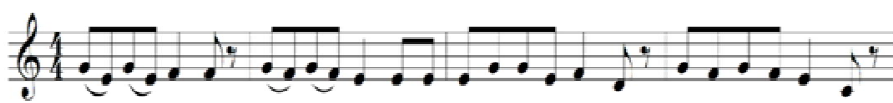

Tuu - tua bos me, tur - tuu boo me,-A - ko-dal bi de Ai - sha Ai-sha-ko wia si - ka

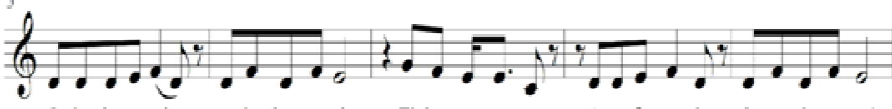

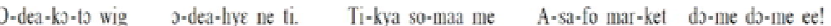

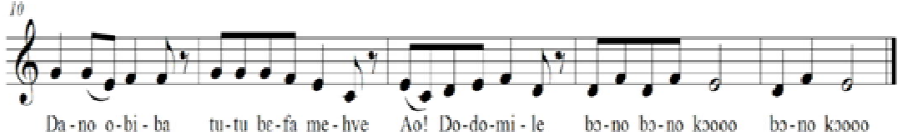

Figure 2: Tuиtuи Вэว Me

5.3.3. Bankyema Akrakuro

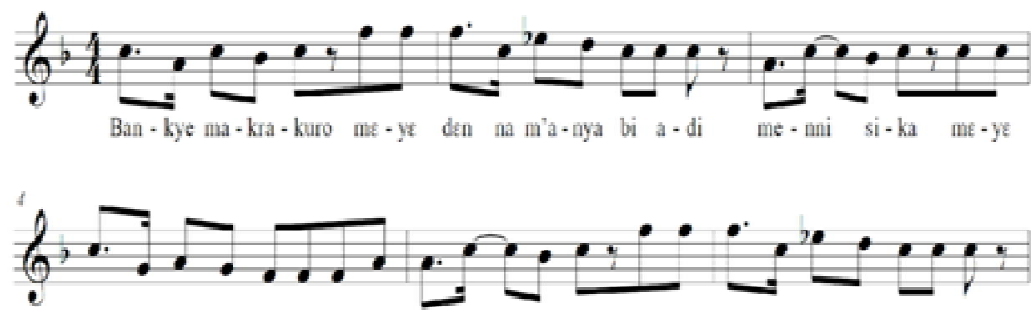

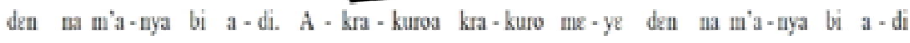

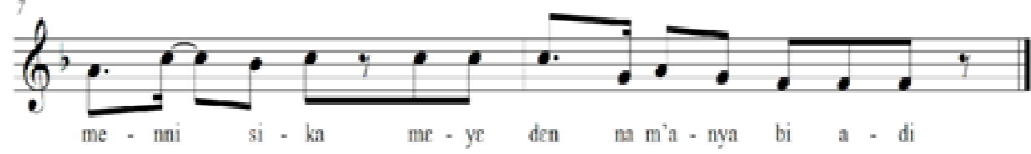

Figure 3: Bankyema Akrakuro 


\subsubsection{Karikokoo}

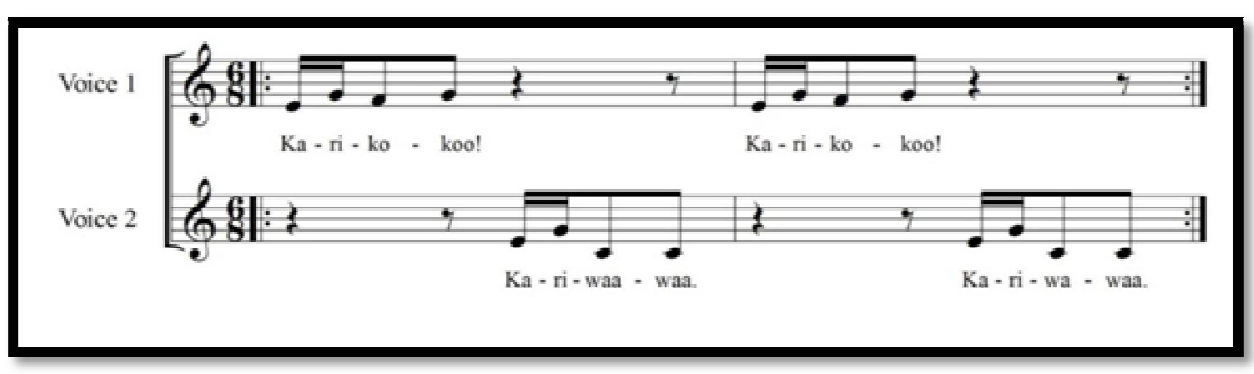

Figure: 4 Karikokoo

Tewbabi folk-game songs are used to portray the past which Traditional music portray the history of the society (Adjepong \& Obeng, 2018; Acquah, 2013) and serve as cultural heritage to younger generations. Musical games (folk-game songs) used in the classroom not only entertain, they also educate learners' cultural heritage. The study revealed that some folk-game songs describe and reveal past events. Again, it came to light that the myth surrounding 'Bankye ma Akrakuro' game as 'Ewe woman introduced 'Cassava dough-nut' to the Bono states' as participants disclosed. The study revealed the history behind Karikokoo game song as how the youth of cocoa dwellers were recruited in loading packed cocoa beans. The Karikokoo game song was used in Creative Arts lesson to teach movement and melody on different occasions. One cannot teach history without the culture of a society (Adjepong \& Obeng, 2018; Nketiah, 2004) which includes our traditional music and games.

The study again revealed that Tewbabi folk-game songs reflect on daily activities. The surest way to transmit our rich culture is to teach children folk songs in schools and inculcate in them its relevance (Adjepong \& Obeng, 2018; Mayona, 2016; Mupetami, 2014; Acquah, 2013; Nketia, 2004). This suggests that playing Tewbabi folk-game songs which have realistic actions and practical oriented affect the lives if both the performers and audiences. In effect, lessons learnt from the history would be part of the daily activities of the individual. The study revealed that actualisation folk-game songs are realistic in action and career oriented. The individual or learner plays musical games to acquire skills which would develop his vocation (Adjepong \& Obeng, 2018).

Music is concerned with combining vocal or instrumental sounds for beauty of form or emotional expression, usually according to cultural standards of rhythm, melody and harmony (Briggs, 2011). Both the simple folk songs and the complex electronic composition belong to the same activity, music (Adjepong \& Obeng, 2018; Mayona, 2016; Nketia, 1974) which both conceptual and auditory factors are present in music of all styles and in all periods of history, throughout the world. The study disclosed Tewbabi folk-game songs embedded with elements of music could serve as training for amateur musicians. Acquah (2013) postulated that traditional music helps children to acquire skills in playing instruments and singing. The study again proved that children sing and play simultaneously and skills development is actualised. Teele and Anhwewoakyire songs have some musical forms (call and response; cantor - chorus) which runs through most of Ghanaian musicians' compositions and these techniques were acquired during their childhood days.

The Tewbabi folk-game songs are also drama oriented. The meaningful gestures exhibited by the performers in playing folk-game songs demonstrated the training they are acquiring which would actualise in realistic acting. The dance in Tewbabi folk-game songs develop the individual's dancing skills which the study revealed. Adjepong and Obeng (2018) describe music aspect of performance as the tool that triggers bodily movement as dance. This had already been confirmed in Acquah (2013) that children learn dance techniques from adults through traditional music performance. In this current study, it was revealed that children dance to develop bodily movement in Teele which acquaint them in various dance skills; both African and Western dance forms. Tewbabi folk-game songs serve as a vehicle for both traditional and contemporary dancers.

\section{Conclusion}

The folk-game songs that exist in Tewbabi community were identified and categorised under two broad themes: transitional and actualisation folk-game songs. These were based on purpose and function of the folk-game songs played. The transitional folk-game songs are the folk-game songs for the purpose of entertainment and preparing individual for an event. It therefore seeks to refresh and entertain children or learners for an event. These are observed in everyday life's activities which include school and home environments. On actualisation folk-game songs, the study made us understand that folk-game songs are realistic in action which brings a particular task in existence. The actualisation folk-game songs function as learning concept or vocation which aid in pursuing a task for future living. The principle underlying the categorisation would assist facilitators to make informed decision on what to teach within the curriculum framework. This would serve as guide in selecting songs for effective teaching which the curriculum for Ghanaian basic schools demands.

\section{References}

i. Acquah, E. O. (2013). New trends in Asafo music performance: Modernity contrasting traditions. Jounal of African Arts and Culture, 1(01), 21-32.

ii. Acquah, E. O., \& Boahen, E. (2015). Compositional processes of Xylafrique: A contemporary art composition based on the Dagaaba gyil of Ghana. Research on Humanities and Social Sciences, 5(22), 136 - 149. 
iii. Acquah, E. O., Sackey-Sam, K. A., \& Annan, J. F. (2015). Use of indigenous musical games and songs in deveoping the total wellbeing of the child. International Journal of Research in Humanities and Social Sciences, 2 (12), 112 123.

iv. Adjepong, B., \& Obeng, P. (2018). The role of performing arts in ghanaian society and its implication fo formal education in primary schools. European Journal of Education studies, 5(6), 221 - 227.

v. Akuoko, D. A. (2010). Children's folk games in Ghana. Retrieved: http://www.abibitumikasa.com/forums/sendmessage.php

vi. Amuah, I. R., Adum-Attah, K., \& Arthur, K. (2017). Music and Dance for colleges of education: principles and practice (Revised ed.). KRAMAD.

vii. Brewu, J. (2009). The Role and Importance of Traditional Music in Patakro Culture (Doctoral dissertation). KNUST, Ghana.

viii. Briggs, M. (2011). Transforming primary QTS Primary profesional studies. (A. Hansen, Ed.). Bell \& Bain Ltd, Glasgow.

ix. Quay, S. E., \& Damico, A. M. (Eds.). (2010). September 11 in Popular Culture: A Guide: A Guide. ABC-CLIO.

x. Creswell, J. W., \& Creswell, J. D. (2019). Research design, qualitaitve, quantitative and mixed methods approaches (5th ed.). London: Sage.

xi. Collins, K. (2007). An introduction to the participatory and non-linear aspects of video games audio. Essays on Sound and Vision, 263-298.

xii. Connellan, K. A. (2019). Dreaming, healing and imaginative arts practice. Routledge.

xiii. Gray, C., \& MacBlain, S. (2015). Learning theories in childhood (2nd ed.). Sage.

xiv. Kapusta, J. (2018). The self-actualization of John adams. Journal of the Society for American Music , 12(3), 317344.

xv. Kayode, S. M. (2013). African folksongs as veritable resource materials for revitalizing music education in Nigerian schools. Research on Humanities \& Social Sciences, 3(10), 22 - 32.

xvi. Mayona, S. (2016). The use of music in enhancing teaching and learning in preschools: case study of selected preschools in Winneba (Unpublished MPhil thesis). University of Education, Winneba.

xvii. Mereku, C. W. (2013). We sing \& learn: A legacy of songs for Ghanaian schools. UEW Music Department.

xviii. Meriwah, C. K. (2017). The aesthetic and socio-cultural values of selected Akan traditional Games. Unpublished MPhil thesis). KNUST, Ghana.

xix. Merriam, A. P. (1964). The Anthropology of Music. Northwestern University Press.

xx. Morford, M. P., \& Lenardon, R. J. (1999). Classical mythology. Oxford University Press, USA.

xxi. Mupetami, L. (2014). Playing traditional childhood games back in the day. Retrieved: https://www.namibian.com.na/index.php?id=119466\&page=archive-read

xxii. Nketia, J. H. (2004). African Art Music. Accra: Afram Publications (Ghana) Limited.

xxiii. Nketia, J. H. (1974). The music of Africa. New York: W. W. Norton \& Co.

xxiv. Nketia, J. H. (1966). Music African Culture, colloquium on Negro Art. Dakar.

xxv. Owusu-Agyemang, K. (2019). The nature of performing arts in ghanaian society for Colleges of Education. Mampong: Akratmax.

xxvi. Schnell, J. (2013, December 5). https://www.thecanadianencyclopedia.ca/en. Retrieved: https://www.thecanadianencyclopedia.ca/en/author/janet-schnell:

xxvii. Skinner, B. F. (1965). Science and human behavior (No. 92904). Simon and Schuster.

xxviii. Warren, D. (1973). The Akan of Ghana.Pointer Limited. 